ORIGINAL RESEARCH

\title{
Transitional Experiences from Clinical Nurse Experts to Novice Nurse Lecturers in the University for Local Development in Thailand: A Phenomenological Study
}

\author{
Boonyada Wongpimoln ${ }^{1}$, Ladda Pholputta ${ }^{1}$, Chaowarit Ngernthaisong ${ }^{2}$, Chawapon Sarnkhaowkhom ${ }^{3}$
}

${ }^{1}$ Faculty of Nursing, Roi Et Rajabhat University, Thailand

${ }^{2}$ Faculty of Nursing, Chulalongkorn University, Thailand

${ }^{3}$ School of Nursing Study, Srisavarindhira Thai Red Cross Institute of Nursing, Thailand

\begin{tabular}{|c|c|}
\hline Article Info & Abstract \\
\hline $\begin{array}{l}\text { Article History: } \\
\text { Received: 20 March } 2021 \\
\text { Revised: 24 July } 2021 \\
\text { Accepted: 28 July } 2021 \\
\text { Online: 27 August } 2021 \\
\text { Keywords: } \\
\text { Clinical nurse experts; nurse } \\
\text { lecturers; transitional experience; } \\
\text { qualitative research; university for } \\
\text { local development } \\
\text { Corresponding Author: } \\
\text { Boonyada Wongpimoln } \\
\text { Faculty of Nursing, Roi Et } \\
\text { Rajabhat University, Thailand } \\
\text { Email: boonyada@reru.ac.th }\end{array}$ & $\begin{array}{l}\text { Background: Nurse lecturers play a vital role in producing professional and } \\
\text { competent nurses through teaching and practicing in universities. It is challenging } \\
\text { for clinical nurse experts to adapt to being nurse lecturers in the university for local } \\
\text { development. Exploring this transitional experience is essential to learn how nurses } \\
\text { adapt themselves to their new roles. } \\
\text { Purpose: This study aimed to describe the transitional experiences from clinical } \\
\text { nurse experts to novice nurse lecturers in the context of the university for local } \\
\text { development. } \\
\text { Methods: The Heideggerian hermeneutic phenomenology was used as a research } \\
\text { methodology. The purposive sampling was utilized to select eight novice nurse } \\
\text { lecturers as participants. Data were ethically collected using in-depth interviews, } \\
\text { observations, field records, and voice recordings. The collected data were then } \\
\text { transcribed verbatim, and a thematic analysis based on van Manen's method was } \\
\text { applied for data analysis. } \\
\text { Results: The findings showed five major themes and four sub-themes, including: } \\
\text { (1) Reasons for becoming a nurse lecturer in the university for local development, } \\
\text { consisting of having a successful career and desiring to serve the community in their } \\
\text { hometown; (2) Learning to work by relying on themselves; (3) Learning and } \\
\text { teaching through an offered service for local development; (4) Seeking support, } \\
\text { consisting of focusing on students as moral support and asking for } \\
\text { recommendations from colleagues; and (5) Confidently moving forward. } \\
\text { Conclusion: Understanding transitional experience from clinical nurse experts to } \\
\text { novice nurse lecturers in the university for local development is very challenging, } \\
\text { especially in managing difficulties in the role transition. It is expected that nursing } \\
\text { schools provide an effective orientation and mentorship programs to help nurse } \\
\text { lecturers promote their role transition efficiently. }\end{array}$ \\
\hline
\end{tabular}

How to cite: Wongpimoln, B., Pholputta, L., Ngernthaisong, C., \& Sarnkhaowkhom, C. (2021). Transitional experiences from clinical nurse experts to novice nurse lecturers in the university for local development in Thailand: A phenomenological study. Nurse Media Journal of Nursing, 11(2), $197-209$. https://doi.org/10.14710/nmjn.v11i2.37366

\section{Introduction}

Presently, the nursing staff and lecturer shortage is a global issue that many countries are facing, including Thailand (American Association of Colleges of Nursing, 2020; Portia, 2019). Thailand has been attempting to solve this issue at a national level by launching many policies, including policies aimed at retaining nurses in the healthcare system. However, due to several factors such as the increasing needs for healthcare caused by an aging society, the complexity of new diseases, the welfares, job satisfaction, and career development, keeping people in the healthcare field has not been as easy as expected (Alotaibi et al., 2016; Artsanthia \& Pomthong, 2018; Gunn et al., 2018; Hariyati et al., 2017; Hoffman, 2019). The quantity and quality of healthcare demands are an ongoing global issue for nurse administrators, clinical nurses, and nurse lecturers (Grainger, 2021; Khunthar, 2014).

Nurse lecturer plays one of the most important roles in producing nurses to serve society. However, there are not enough nurse lecturers to teach nursing students at a suitable lecturer per student ratio. The ratio for a full-time nurse lecturer equivalent to a student at this moment is not 
more than 1:6 (Gazette of Thailand Nursing and Midwifery Council, 2019). Therefore, Thailand's capacity to produce nurses is not in line with society's needs (Aroonsang et al., 2012). Also, the Thai Nursing and Midwifery Council (Gazette of Thailand Nursing and Midwifery Council, 2019) has determined that the qualifications for a full or part-time nurse lecturers in colleges or universities should be at least a master's degree in nursing or a program related to the subject matter being taught (Bureau of Policy and Strategy Ministry of Public Health, 2017). These requirements mainly help to clarify the basic qualities that nurse lecturers should have to do their job efficiently.

From all above, it is important to remember that nursing faculties have to deal with a variety of job descriptions, which can be directly or indirectly connected to the teaching, such as teaching both in the theoretical and practical fields, conducting research, or even providing academic services (Bureau of Policy and Strategy Ministry of Public Health, 2017). Moreover, it should be considered that nurses need to do urgent jobs without any preparation, which can ultimately cause stress. Therefore, the nurse lecturers need more time to prepare nurses to be ready for any activities through their teaching, research, or the provision of academic services. These abilities are important because higher education aims to produce human resources who are competent in any professions (Roongruangsri \& Sngounsiritham, 2015). Consequently, one of the most important responsibilities of a nurse lecturer is advising and coaching nursing students to fulfill their potential as professional nurses (Mthiyanee \& Habedi, 2018). As a result, it is argued that nurse lecturers play a crucial role in offering a successful nursing education focusing on producing professional and competent nurses for the society.

However, in order to teach students, the transitional experience from a clinical nurse to a nurse lecturer is a complex process and, unfortunately, involves a long period of self-adapting. Thomas et al. (2019) reported that chronic stress due to various reasons such as employment requirements, working in an understaffed environment, and lack of support could cause nurse faculty burnout which leads to resignation. A study highlighting this transitional experience by Raetong (2012) showed that former nurse practitioners felt stressed, anxious, nervous, bored, exhausted, and confused with their new roles. On the other hand, they felt happy when getting any positive reinforcement such as praise, and felt pride and gratitude toward their parents as they were able to experience the joys of working as nurses. Because of this experience, during the nursing role transition, they had solutions to deal with any situations, which helped them understand situations better, accept mistakes and difficult moments, become self-reliant and confident enough to seek any advice, and release tension so that they would not have to endure any psychological problems (Raetong, 2012). Besides, this experience also taught them how to deal with unpleasant behaviors of colleagues when faced with uncertainty about them as novice lecturers to be able to fulfill one's academic expectations, difficult challenges, time limitations, and unfriendly behavior from senior colleagues (Heydari et al., 2015). Therefore, it is strongly believed that the role transition from clinical nurses to nurse lecturers needs to be made easier and improved appropriately through the provision of a focused assignment. In addition, the nurse lecturers should, at the same time, be a qualified person, so the recruiting process must be focused on evaluating the educational qualifications, work experience, personal potential, personal attitude, and more (Summawart, 2000). For example, the nurse lecturers need to have knowledge and experiences related to their teaching subject, which they can share with their students. Their knowledge should be in line with the learning outcomes. Nurse lecturers should demonstrate that they can cultivate their students to be competent nurses, so that the needs of society can be fulfilled efficiently. Another reason why the nursing role transition is important is that if the nurse lecturers cannot adapt themselves to their new roles, even if they are an expert in nursing, they may face reality shock and burnout respectively (Summawart, 2000).

As aforementioned, the differences in roles between clinical nurse experts and nurse lecturers are obvious. It is, therefore, challenging for clinical nurse experts to adapt to being nurse lecturers in the university for local development. If they cannot overcome the adaptation process, it leads to stress, anxiety, and confusion (Kuewong \& Oumtanee, 2017; Owens, 2017). Consequently, they would probably quit the nursing educational system, which contributes to the shortage of nurse educators, and as a result, the nursing students will not be taught by nurse lecturers who will share one's rare and valuable knowledge, skills, and attitudes. Accordingly, this study aimed to describe the transitional experiences from clinical nurse experts to novice nurse lecturers in the context of the university for local development. It is expected that this study could provide insight

Copyright (C) 2021, NMJN, e-ISSN 2406-8799, p-ISSN 2087-7811 
for nursing administrators, nursing lecturers, and clinical nurses to develop plans and guidelines for supporting clinical nurses in their role transition to be nurse lecturers in the university for local development.

\section{Methods}

\subsection{Research design}

A qualitative study was conducted using a Heideggerian phenomenological hermeneutic method (Heidegger, 1962) to describe the transitional experiences from clinical nurse experts to novice nurse lecturers in the context of the university for local development in Thailand. As phenomenology is an exploratory approach, it does not seek to achieve either reliability or validity among a broad population group since it typically uses a small sample (Polit \& Beck, 2004).

\subsection{Setting and participants}

This study was carried out in a university for local development in the northeast of Thailand. Purposive sampling was used to select nurse lecturers as participants at the beginning of sample selection. Then, snowball sampling was applied after each interview to obtain the least of participants. Eight participants were selected based on the inclusion criteria. The inclusion criteria were as follows: (1) the participants had to have been working at the university for local development in the northeast of Thailand for at least one year; (2) they first started to work as nurse lecturers at the university for local development in the northeast of Thailand; (3) nurse lecturers had more than five years of clinical nurse experiences; and (4) they were also willing to participate in the study. The number of participants in this study was determined based on the level of redundancy. After eight participants, there was no new data emerging, or data saturation was reached; therefore, the researchers stopped the data collection.

\subsection{Data collection}

As a first step, a research draft was sent to an ethical review committee and the dean of the faculty of nursing to ask for approval. Then, the researchers contacted the first participant who met the criteria and informed the participant about the purpose and method of the study. Next, the researchers and participant made an appointment for an interview at the participant's convenience. Data were ethically collected from 10 January until 30 June 2020 by face-to-face interviews for four participants. The rest were interviewed using video conferencing platforms due to the implementation of remote working strategy by the Thai government during the COVID19 pandemic. The in-depth interview was conducted by starting with general questions to establish trust and followed by unstructured questions. The main questions included; "What were your inspirations of transitioning your career from being a clinical nurse to be a nurse lecturer?", "How do you feel when you first started in your role as a nursing lecturer?", "How can you adapt yourself into your new role?", and "Do you have anything else that you would like to share with me?" The main questions were asked and were answered through storytelling by the participants until enough information was collected. The interview took 45-6o minutes each time, and 1-2 rounds were held for each participant in which demographic data and field notes were recorded. Participants were also asked for permission to contact further if there was a need to re-interview them at a later date in order to clarify information and ensure the researchers had interpreted their words correctly.

\subsection{Data analysis}

The collected data were analyzed using the van Manen's thematic analysis method to be summarized into sub-themes and main themes from the lived experiences (van Manen, 1990). The researchers followed six steps of van Manen's approach (van Manen, 2015), including: (1) Turning the nature of lived experience by formulating the research question of this study; (2) Investigating the participants' experience using an in-depth interview with unstructured questions; (3) Reflecting on the essential themes by listening carefully to the recordings repeatedly, and reading carefully for verbatim transcription to develop initial themes; (4) Describing the phenomena in the art of writing and rewriting by re-reading the initial themes and constant revising and refining thought; (5) Maintaining a strong and oriented relation to the phenomenon by striving to remain focused on the research questions; and (6) Balancing the research context by considering the parts and the whole themes by isolating thematic statements 
to develop final themes that represent the lived experience. Subsequently, the themes were reflected upon, and the phenomena were done manually.

\subsection{Trustworthiness}

Trustworthiness is important to increase confidence that the study findings reflect the participants' perspectives (Guba \& Lincoln, 1994). As suggested by Guba and Lincoln (1994), various strategies were used to enhance the trustworthiness of the study findings, as follows: (1) Credibility: after a verbatim transcription had been created between the interviewee and the researcher, the researcher sent the transcripts back to all participants so that the content could be checked. The participants confirmed that what was in the transcription was a fair account of what was covered, and no revisions were needed. Furthermore, the analyzed findings were proved by three experts who were members of nursing faculties and had the experience of conducting qualitative research, and their findings were expressed in a peer debriefing. Some minor suggestions made the findings more complete after revision; (2) Transferability: the researcher carefully completed the findings by analyzing the information and including all data; (3) Dependability: the researcher used several tools to collect data such as a voice recorder, demographic data, and field note record forms to make sure that all data that was collected and recorded; and (4) Conformability: systematic data collection and analysis were used and that data was then checked and compared as part of an audit trail.

\subsection{Ethical considerations}

Informed consent was obtained both orally and in written from all participants. The researcher was committed to keeping their personal information, interview data, and anonymity confidential. Their identities were kept confidential using the nurse lecturer coding given to the participants based on the interview order. This study was approved by the Research Ethics Committee of Roi Et Rajabhat University. The certification number was 019/2562.

\section{Results}

\subsection{Characteristics of participants}

The participants included eight nurse lecturers. One-half of the participants were in the 3040 age group while one was in the 41-50 age range, and three were in the 51-60 age range. All participants were female and graduated with at least a master's degree. The participants' years of clinical nurse experiences ranged from 6 to 25 years, and their nurse lecturer experiences ranged from 1 to 10 years, as can be seen in Table 1 .

Table 1. Demographic characteristics of the participants $(n=8)$

\begin{tabular}{lcc}
\hline \multicolumn{1}{c}{ Demographic characteristics } & $\mathrm{f}$ & $\%$ \\
\hline Sex & & \\
$\quad$ Male & 0 & $\mathrm{o}$ \\
$\quad$ Female & 8 & 100 \\
Age (years) & & \\
$\quad 30-40$ & 4 & 50 \\
$\quad 41-50$ & 1 & 12.5 \\
$\quad 51-60$ & 3 & 37.5 \\
Educational background & & \\
$\quad$ Master degree & 8 & 100 \\
Clinical nurse experience (years) & & \\
$\quad$ 1-10 & 4 & 50 \\
11-20 & 1 & 12.5 \\
$\quad>21$ & 3 & 37.5 \\
Nurse lecturer experience & & \\
1-5 & 3 & 37.5 \\
6-10 & 5 & 62.5 \\
\hline
\end{tabular}


3.2 Emerging themes

The findings consisted of five major themes and four sub-themes, as presented in Figure 1.

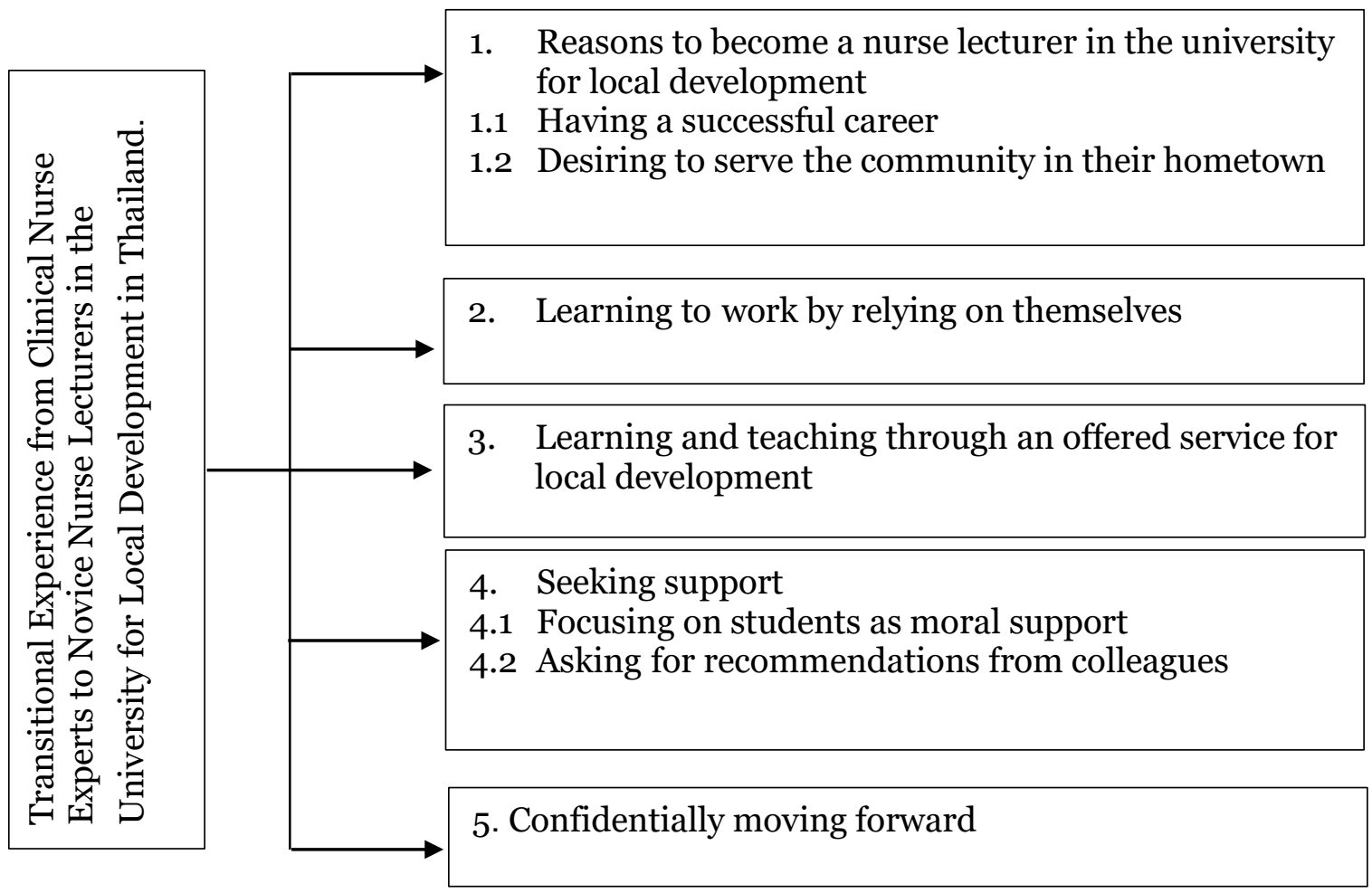

Figure 1. The major themes and sub-themes among the findings

The findings regarding the transitional experiences from clinical nurse experts to novice nurse lecturers in the university for local development in Thailand were presented as follows:

\subsubsection{Reasons for becoming a nurse lecturer in the university for local development}

Making a crucial decision to be nurse lecturers was an important turning point in the life of clinical nurses. There were two main reasons why they decided to be nurse lecturers as stated below:

\subsubsection{Having a successful career}

After applying to become nurse lecturers at the nursing faculty, the nurses automatically became university staff members without having to be put on any waiting list compared with the other faculties' staff members. A nursing academic career had a clear pathway to success because there was no limit on the available number of positions. Moreover, nursing faculties did not need to compete with other colleagues to get into a higher position. Therefore, people could qualify to become nurse lecturers based on their academic performances, research, and nursing education experiences as long as they had been meeting the national criteria. Hence, it meant that a successful career was possible if people realized their potential.

“...When working as a clinical nurse before, I was stuck on the 7 th level of the career ladder, and I couldn't achieve a higher level because there was no available position. At that time, my salary was limited even while I continued to work there, and my salary did not increase. In contrast, if I work as a nursing lecturer, the salary will be increased every year. If I am hardworking and my qualifications are accepted, I can level up for an academic position. It truly depends on my potential..." (Participant 2)

“...If I work here as a nursing lecturer, I can immediately become a permanent member of the university's staff while this would not be possible for staff members from another faculty. This is the benefit of being a nurse lecturer here, and it's motivating because I am provided 
with the opportunity to get an academic position. There is no limitation, as it all depends on my potential..." (Participant 3)

\subsubsection{Desiring to serve the community in their hometown}

Many clinical nurses would like to be nurse lecturers because they had a passion for serving the community in their hometown. Therefore, they decided to be nurse lecturers to teach the local nursing students to be competent nurses to serve their hometown passionately. They wanted to teach and cultivate the nursing students through their knowledge, skills, experiences, and ethical points of view holistically and professionally.

“...I have a lot of knowledge, skills, and experiences to deliver to the next generation. I want to share them and be their role model. By teaching novice nursing students, I believe it is the best choice to cultivate a proper practice and culture of working focused on morals and ethics to provide competent nurses. Furthermore, I am of the thought that producing good nurses is the best way that I can serve my hometown. This is because I believe that before my retirement, I have to return all that I have learned and gained in life to society, especially my hometown..." (Participant 1)

"...I want to be a teacher here because I want to be a part of serving the community in my hometown. I am qualified to be a nursing teacher because I have graduated with a master degree and I love to work in an academic field...” (Participant 7)

\subsubsection{Learning to work by relying on themselves}

At the start of learning something new or changing to a new role, sometimes the nurse lecturers at the nursing faculty had to learn about their work by themselves because there was not a stable system yet that instructed them how to teach and do their jobs. Therefore, they had to apply their knowledge to work in their working environment. Moreover, some nurse lecturers took courses by themselves so that they could understand the Thai Qualification Framework for Higher Education (TQF) [TQF is a framework and document used in Thailand to store information about the upcoming courses as evidence to ensure transparency and maintain the efficiency of teaching and learning management with the goal of improving the quality of learning and learned; TQF1-6]. In addition, some nurse lecturers learned to teach nursing students in the practicum field by evaluating themselves and their students every day and writing about their students' performances in their notebooks by writing a summary of their performances and providing them with grades. On the other hand, other nurse lecturers learned to teach by using student-centered techniques by listening to their nursing students' voices and providing them with knowledge according to the students' needs and TQF 4 [TQF4 was a document about a field or practical learning experience which includes general information about the subject, the subject's propose, the subject content and operation, academic performance development, lesson plans, and evaluation methods, teaching resources, and methods of evaluating and improving the quality of the learning experience].

“...The faculty system is not stable yet. No one has trained me to teach. I enrolled to study in the faculty of education and strenuously had to do this by myself. I received a 1-year educational certificate and teaching certificate from the faculty of education. I learned about the curriculum and how to teach courses. When I studied, I just thought that I needed TQF1, TQF2, but I learned that it could also be TQF3, 4, 5, or 6, respectively. I know more about them now, but the problem, at the beginning, was that no one helped me with my training, and no one was taking care of me..." (Participant 1)

“...I did not have a teaching model for all processes in the practicum field. I had to rely on myself to teach the nursing students. I evaluated myself and my students every day and wrote important points about the students' performance in the notebook so that I could summarize their performance and lastly gave them a grade. I used student center techniques, and I provided them with knowledge according to the students' needs and TQF 4 . I could do it, but I was quite slow. I felt when no one could come to guide me; it was unfair to the students as they should be learning from a confident teacher..." (Participant 4) 


\subsubsection{Learning and teaching through an offered service for local development}

The nurse lectures had to work following the strategies of the university, which were focused on local community development based on the creation of local development strategies to encourage local community participation. These strategies are aimed at developing elderly caregivers so that they could collaborate with the villagers to take care of their community. Besides, the strategies also cover providing healthcare officials to people of all stages of life from birth to death holistically. The examples range from arranging training programs for health volunteers so that they would know how to take care of children in the community, to training programs for teenagers so that they would know how to take care of older adults empathically by being a trainer or supervisor. To achieve this, the nurse lecturers need to establish a good relationship with healthcare professionals at the health-promoting hospitals, health volunteers, community leaders, and villagers to ensure that the programs are developed collaboratively and sustainably. Meanwhile, the nurse lecturers needed to teach the nursing students to learn from these community development programs through "service learning." The "service learning" program was a type of teaching and learning which mixed both academic and practical components by encouraging the students to learn from a real situation while developing their community.

“...Besides teaching, I have to develop the community based on the university's strategies. For instance, I had to see the director and staff of the health-promoting hospital near our university. I also needed to work with the health volunteers in the community because I had to deal with them to arrange the development of a program that focused on training the caregivers of older adults, which would encourage them to take care of older adults in their community. I had to deal with these caregivers until the end of this project, so maintaining a good relationship with them was important to establish trust and become part of a harmonious community...” (Participant 2)

“...My nursing students also participated in the local development activities based on the strategies of our university. For example, the students demonstrated and taught people to do exercise in the community and held awareness campaigns about dengue fever. They were taught this before utilizing the theory they had been taught in the community step by step, which is also known as integrated learning by doing in real life what they had been taught about developing or improving their communities...” (Participant 8)

\subsubsection{Seeking support}

When obtaining a role in the nursing faculty, there were many obstacles that nurse lecturers had to encounter, especially regarding the work that they had not done before. Therefore, learning and understanding the tasks which became their responsibility was what matters most. For that reason, the nurse lecturers used many approaches to improve themselves, understand the contexts nursing students might face in the future, and recognize their responsibilities. There were two sub-themes to the seeking support option as shown below;

\subsubsection{Focusing on students as moral support}

In the adaptation period, a new nurse lecturer had to learn about the work, the people, and also the culture of the organization and know how to deal with problems. Sometimes when there was a problem that affects the teaching, it could make a nurse lecturer feel tired, but looking at the students and thinking about what the students would gain from their role, might encourage them to keep going. Additionally, lively and innocent students have made their moral support to do their work. This led to some nurse lecturers choosing the way not to care about events that could not be changed, such as unfriendly senior colleagues, but it did make them change their vision of how they saw the world by having positive thoughts and improving themselves each day to teach their students satisfactorily.

“...I used to suffer from an unclear way of how my classes were audited as my lecture was occasionally interrupted by senior nursing staff members of the faculty, which made my class not run smoothly, and I felt so upset. Despite this, the students were the reason why I wanted to stay here at the nursing faculty since they were lively and supported me even if I was not 
good at teaching. Sometimes they gave me moral support by cheering me up during my lecture or paying attention in class as they knew I was nervous. When I looked at their shining eyes, it made me want to try harder as I felt I had become a nurse lecturer here to teach them to be good nurses, so they were my inspiration at times...” (Participant 5)

\subsubsection{Asking for recommendations from colleagues}

Starting to work in a new role was not that easy, so asking for recommendations from colleagues could help nurse lecturers to understand better because some colleagues might have a lot of experience.

“...My colleague always advised me to find a way to calculate the grades and create a Thai qualification framework (TQF). Even though I tried it by myself first, if I could not do it, I would ask my colleague to teach me..." (Participant1)

“...If there was a task or a context that I did not understand yet, I would always ask my colleague who was my friend since she had more experience than me. My colleague used to be a secretary of the chancellor, and as the way the paperwork had to be done and very strict guidelines, I would ask her for help with the paperwork...” (Participant 6)

\subsubsection{Confidently moving forward}

Working as a clinical nurse required a different working style compared to working as a nurse lecturer. This was because a clinical nurse would try to save lives and care for people every day and finish that duty at the end of each day. Meanwhile, a nurse lecturer would do academic work endlessly. Therefore, it was important that the nurse lecturers learned to adapt themselves and understand their role so that they could manage their time to have a good work-life balance and a better quality of life by learning how to do their work more smoothly. Some of them said that when working as nurse lecturers, they might be faced with obstacles sometimes, but if they looked at them as challenges, they could fix any situation. These adaptations could lead them to be more confident to work smoothly at the nursing faculty.

“...When being a clinical nurse and taking care of patient's lives, the duty is finished once their shift has finished. They only had to deal with problems during their working time, but this was different for a teacher as they had many other responsibilities to fulfill. For example, I worked as a member of the student development committee. Therefore, there would be more responsibilities as I had to take care of the students from the first orientation day until they graduate. When they had any problems, including family, study, or financial problems, I was the person who tried to help my students to overcome all their obstacles as much as I could. This is an endless cycle..." (Participant 2)

“...Once I gained more understanding about the roles at the nursing faculty, I knew how to improve myself academically and fulfill my research requirements. I felt happier involving myself in academic services and playing a part in preserving the national arts and cultures. After adaption period I can do exercise and sleep properly..." (Participant6)

“...I was so excited for my first class, so I had prepared everything completely. For my second class, it was a lot better because I had more confidence. After a year passed, I understood almost everything, I knew how to teach, to train my students, and manage my schedule to conduct my research and provide service-learning. When I was faced with obstacles, I looked at them as challenges enabling me to learn from any situation and fix any issues..." (Participant 5)

\section{Discussion}

The study found five major themes and four subcategories. They were reasons to become a nurse lecturer in the university for local development, learning to work by relying on themselves, learning and teaching through an offered service for local development, seeking support, and confidentially moving forward. 


\subsection{Reasons to become a nurse lecturer in the university for local development}

This study showed that there are many reasons to become nurse lecturers in the university for local development, including having a successful career and desiring to serve the community in one's hometown. Likewise, Al-Qahtani et al. (2020) showed that the career ladder contributes to the job satisfaction of nurses. Similarly, Halstead and Frank (2017) noted that an academic career in nursing education as a nurse lecturer is a very rewarding career to have as successful career. In addition, nurse lecturers had the most respected educators on campuses of higher education. Being a nurse lecturer to serve the community in one's hometown can reach and maintain self-esteem. The finding is relevant that people strive to feel good or seek to maintain self-esteem, which is fundamental to human nature (Yang et al., 2016).

\subsection{Learning to work by relying on themselves}

This study confirms that during the transition period, novice nurse lecturers learn to work by relying on themselves, and lacking support can be a reason for nurse lecturer burnout (Thomas et al., 2019). Transitions from the clinical nurse role to nurse lecturers need effective selfadaptation. Otherwise, they might be confronted with culture shock even if they have worked as an expert clinical nurse before. Kuewong and Oumtanee (2017) also noted that new nurses faced stress when they started working in a new role in the intensive care unit. This might result in having some pressure, feeling unconfident, or burning out, which can cause them to leave their job. On the other hand, if the clinical nurses have studied to do or have been trained to teach the nursing program, they may have more understanding of teaching in nursing science both theoretically and practically. They may also have more confidence to work as a nurse lecturer. Likewise, Cooley and De Gagne (2016) mentioned that to stop these barriers, an internship could facilitate the characteristics of transformative learning experiences. Internship programs are believed to be a necessary link that can be used to create academic environments that contribute to the development of competence in a novice nurse lecturer. This is related to a study by Chargualaf et al. (2017) which argued that the transition from military nurses to nurse lecturers included acknowledgment of the reality of the academic culture, appreciation for the journey that was needed to be made to bridge the gap, and the culmination of a new identity to survive the new role. Therefore, the recognition of this transition and the strengths that these nurses can offer shows the necessity for focused orientation programs to increase the retention of new nurse lecturers at the faculty.

\subsection{Learning and teaching through an offered service for local development}

This study revealed that nurse lecturers must learn and teach through an offered service for local development. When working as nurse lecturers, the lecturers face several responsibilities, which might make it difficult to do their unfamiliar job in the beginning. Moreover, they have to come up with projects to develop the local community according to the university's mission, and strategies focused on the socio-economic, environmental, and educational development of their society, so that any issues can be solved continuously and sustainably (Dapong, 2018). Similarly, the nurse lecturers should follow the university's strategies to develop the local community by collaborating with the villagers to gain sustainable development (Thanisorn, 2018). So, Nurse lecturers need to learn how to adapt themselves to build a strong relationship with the people in their community. Besides, community-based research focusing on community strength stated that an ideal situation for the development of community collaboration between the lecturers, faculties and the members of the community was required so that they could work together to focus on certain issues in the community directly in order to create real sustainability (Pavida \& Duangkamol, 2019). Thus, it can be said that local development is one of the nurse lecturers' responsibilities, and it is necessary for them to deliver practical improvements so that the university can contribute to social and sustainable regional development. Importantly, service learning should be implemented, which is the process of teaching through the collaboration of the educational institutes, students, and community through which they all work on activities that contribute to changes in the community. This offers students the opportunity to learn from real situations, and the educational institutes are able to pass on knowledge to the community in aid of their sustainable development. However, it is important to note that this learning method requires a good relationship between the educational institute and the community. It also needs to be monitored continuously by listening to feedback and analyzing the results systematically 
because the main responsibilities of the university as the educational institute are producing competent students and providing academic services to society (Thaneenat, 2018). It is obvious to see that the nurse lecturers need to have a good relationship with the community when teaching students and providing academic services based on the university's mission and strategies.

\subsection{Seeking support}

When former nurses start to work in their new role, they need to adapt themselves psychologically. Therefore, they need to adjust their perspectives toward teaching, coaching, and training. As the study of nursing role transition from a head nurse to a nurse manager shows, it is important to possess psychological readiness to face any issues, and lecturers should be able to manage those problems wisely (Charoengid \& Oumtanee, 2017). It is similar to a study by SvastdiXuto and Wangsukpisan (2019), that investigated the transition experiences of initial clinical nursing students. They found that before gaining professional experience, the students felt anxiety, worry, and stress. However, when they tried to face the challenges during practical assignments, they felt challenged, which pushed them to learn from their friends, teachers, fellow nurses, and most importantly, their practical experiences on the ward, which ultimately helped them gain more understanding about the professional nurse job role. Additionally, nurse lecturers have their students be encouraged and their colleagues to guide their work. This is similar to Mower (2017) who found that socialization with peers and other people in the organization will be helpful to new educators. Likewise, Elizabeth (2018) noted that inadequate peer support was a barrier to successful transition across practice and academic settings. However, Hunt (2018) found that getting support from a mentor could help the new nurse educators to face a transition period into the academic setting smoothly. Importantly, without mentoring, these nurse educators might not have remained in academia. This is similar to Summers (2017) who reported that orientation programs, mentor support, clarity about role expectations, and ongoing feedback on performance during the transition period were necessary for academic organizations to retain excellent nurse educators in the university.

\subsection{Confidentially moving forward}

The results of this study found that after the new nurse lecturers were able to adapt themselves to work confidently, they would try to improve themselves in terms of knowledge, skills, and experiences. Transitions represent opportunities rather than losses (Patterson, 2020). In addition, Budin (2017) noted that confidence comes from feelings of well-being, acceptance of body and mind, and belief in one's own ability, skills, and experience. Therefore, when people follow these aspects of self-development, they might feel confident and happy to work when adapting to a new role which can increase the effectiveness of the nursing education system.

In addition, after moving through the transition period from clinical nurses to nurse lecturers, the stress and anxiety will be released, and they will feel more satisfied with their job. This is in line with Baker and Alshehri (2017), they reported that the stress factors were highly correlated with job satisfaction. Job satisfaction is an essential component of improving job performance and maintaining the overall work quality in any organization. It is well established that persons who are satisfied with their job tend to be more creative and innovative for better organizational performance (Sapkota et al., 2019). Moreover, job satisfaction results from the work-life balance, contributing to a healthy, happy, and successful life (Kasbuntoro et al., 2020; Soomro et al., 2018).

\section{Implication and limitations}

This study provides interesting findings that are vital to understanding the phenomenon of the role transition from clinical nurse experts to novice nurse lecturers in the university for local development. Considering the various obstacles that clinical nurse experts experienced in their transition to novice nurse lecturers, it is essential for nursing school administrators to provide an effective orientation and mentorship program to promote the role transition efficiently.

This study has limitations. It was conducted at a local development university in Thailand, which has a specific cultural context. In addition, the experience of novice nurse lecturers at general universities and private universities was not explored in this study. Therefore, the findings might not be transferable beyond the local development context. Therefore, further studies might 
be conducting by developing the plan and guidelines to support clinical nurse experts in their role transition to be new nurse lecturers effectively.

\section{Conclusion}

This study showed that the transitional experiences from clinical nurse experts to novice nurse lecturers in the university for local development is very challenging for both nursing administrators and lecturers due to the role transition. Learning to work with a community is needed to complete the university for development's mission for sustainable community development. Consequently, effective training and orientation or mentorship programs will be beneficial to support new nurse lecturers to prevent issues such as stress, anxiety, and confusion so that community development can be enhanced. Moreover, after they have passed the phase of adapting themselves and have readily learned how to improve themselves, they can work with confidence. Consequently, it is an important determiner in the nursing role transition as it either pushes the clinical nurses to give up on becoming nurse lecturers, or, on the other hand, may encourage clinical nurses to become nurse lecturers in the university for local development. Thus, the effectiveness of the university's support to the nursing role transition can significantly increase the quality and quantity of nurse lecturers to produce competent nurses for society and lead to a successful transition.

\section{Acknowledgment}

The authors wish to express their gratitude to all participants. This study could not be completed without the willing participation from the participants. This study was funded by the Faculty of Nursing, Roi Et Rajabhat University, Thailand.

\section{Author's contribution}

BW, the principal investigator and corresponding author, performed the research design, data collection, data analysis, drafted and revised the manuscript. LP, co-researcher, was involved in literature review and data collection. $\mathrm{CN}$, co-researcher, was involved in data collection and revision of the manuscript. CS, co-researcher, was involved in data analysis and revision of the manuscript. All of the authors have approved the submitted and published version of this manuscript.

\section{Conflict of interest}

There is no conflict of interest to declare in this study.

\section{References}

Alotaibi, J., Paliadelis, P.S., \& Valenzuela, F.R. (2016). Factors that affect the job satisfaction of Saudi Arabian nurses. Journal of Nursing Management, 24(3), 275-282. https://doi.org/10.1111/jonm.12327

Al-Qahtani, A.H., Stirling, B., \& Forgrave, D. (2020). The impact of job satisfaction on nurses' work lives: A literature review. QScience Connect, 1(1), 1-11. https://doi.org/10.5339/connect.2020.1

American Association of Colleges of Nursing. (2020, September). Nursing faculty shortage. https://www.aacnnursing.org/Portals/42/News/Factsheets/Faculty-ShortageFactsheet.pdf

Aroonsang, P., Sritanyarat, W., Nansupawat, R., Kaewpan, W., Lertrat, P., \& Isaramalai, S. (2012). Work and health conditions of retired nursing lecturers still in nursing schools' employ. Thai $\begin{array}{lllll}\text { Journal of Nursing 6ouncil, 27(2), } & \text { 63-80. }\end{array}$ https://www.nur.psu.ac.th/researchdb/file_warasarn/172journal2.pdf

Artsanthia, J., \& Pomthong, R. (2018). The trend of elderly care in 21st century: Challenging in nursing care. Journal of The Royal Thai Army Nurses, 19(1), 39-46.

Baker, O. G. \& Alshehri, B. D. (2017). The relationship between job stress and job satisfaction among Saudi nurses: A cross-sectional study. Nurse Media Journal of Nursing, 1O(3), 292305. https://doi.org/10.14710/nmjn.v10i3.32767

Budin, W. C. (2017). Building confidence. The Journal of Perinatal Education, 26(3), 107-109. https://doi.org/10.1891/1058-1243.26.3.107 
Bureau of Policy and Strategy Ministry of Public Health. (2017). Public health statistics. Bureau of Policy and Strategy.

Chargualaf, A. K., Elliott, B., \& Patterson, B. (2017). The transition from military nurse to nurse faculty: A descriptive study. International Journal of Nursing Education Scholarship, 14(1), 1-7. https://doi.org/10.1515/ijnes-2017-0027

Charoengid, W., \& Oumtanee, A. (2017). Experiences of role transition from a head of department to a manager of nursing division in private hospital. Journal of The Royal Thai Army Nurses, 18(supplement), 138-146.

Dapong R. (2018, 11 October). 20 years Rajabhat university strategy (2017-2036 for local development. https://www.aru.ac.th/rdi/images/pdf/Plan-rdi1_1.pdf

Cooley, S.S, \& De Gagne J.C, (2016). Transformative experience: Developing competence in novice nursing faculty. Journal of Nursing Education, 55(2), 9610o.https://doi.org/10.3928/01484834-20160114-07

Elizabeth, F. (2018). Transition from clinical to educator roles in nursing: An integrative review. Journal for Nurses in Professional Development, 34(2), $67-77$. https://doi.org/10.1097/NND.0000000000000436

Gazette of Thailand Nursing and Midwifery Council. (2019, 19 August). The standard of Thailand nursing education. https://www.tnmc.or.th/images/userfiles/files/T_o053.PDF

Grainger, L. (2021, 25 February). Nursing faculty shortage in the U.S.: Has a pandemic compounded an existing problem? https://www.wolterskluwer.com/en/expertinsights/nursing-faculty-shortage-in-the-us

Guba, E.G, \& Lincoln, Y.S. (1994). Handbook of qualitative research. Sage

Gunn, V., Muntaner, C., Villeneuve, M., Chung, H., Gea-Sanchez, \& M. (2018). Nursing professionalization and welfare state policies: A critical review of structural factors influencing the development of nursing and the nursing workforce. Nursing Inquiry, 26(1), 1-12. https://doi.org/10.1111/nin.12263

Halstead, J. A., \& Frank, B. (2017). Pathways to a nursing education career (2nd Ed). Springer Publishing Company.

Hariyati, T. S., Igarash, K., Fujinami, Y., Susilaningsih, F. S., \& Prayenti. (2017). Correlation between career ladder, continuing professional development and nurse satisfaction: A case study in Indonesia. International Journal of Caring Sciences, 10(3), 1490-1497. http://www.internationaljournalofcaringsciences.org/docs/42_hariyati_original_10_3.pdf

Heidegger, M. (1962). Being and time. Yale University Press.

Heydari, A., Hosseini, S.M., \& Moonaghi, H.K. (2015). Lived experiences of Iranian novice nursing faculty in their professional roles. Global Journal of Health Science, 7(6), 138-145. https://doi.org/10.5539/gjhs.v7n6p138

Hoffman, D. E. (2019). Transitional experiences: From clinical nurse to nurse faculty. Journal of Nursing Education, 58(5), 260-265. https://doi:10.3928/01484834-20190422-03

Hunt, D. D. (2018). The new nurse educator (2nd Ed.). Springer Publishing Company.

Kasbuntoro, K., Irma, D., Maemunah, D., Mahfud, I., Fahlev, M., \& Parashakti, R. D. (2020). Work-life balance and job satisfaction: A case study of employees on banking companies in Jakarta. International Journal of Control and Automation, 13(4), 439-451. http://sersc.org/journals/index.php/IJCA/article/view/16461/8242

Khunthar, A. (2014). The impacts and solutions to nursing workforce shortage in Thailand. Journal of Nursing Science, 32(1), 81-91.

Kuewong, G., \& Oumtanee, A. (2017). Stress of newly graduated nurses working at an intensive care unit. Journal of The Royal Thai Army Nurses, 18(supplement), 158-165.

Mower, J. (2017). Transitioning from perioperative staff nurse to perioperative educator. AORN Journal, 106(2), 111-120. https://doi.org/10.1016/j.aorn.2017.06.005

Mthiyane, G. N., \& Habedi, D. S. (2018). The experiences of nurse educators in implementing evidence-based practice in teaching and learning. Journal of Interdisciplinary Health Sciences, 23(1), 1-9. https://doi.org/10.4102/hsag.v23io.1177

Owens, J. M. (2017). Secondary stress in nurse educators. Teaching and Learning in Nursing, 12(3), 214-215. https://doi.org/10.1016/j.teln.2017.02.004

Pavida, C., \& Duangkamol, P. T. (2019). Community-based research for the community strength. King Mongkut's Agricultural Journal, 36(2), 152-161. 
Patterson, B. J. (2020). A time of transition for nursing education perspectives. Nursing Education Perspectives, 41(2), 75-76. https://doi.org/10.1097/01.nep.0000000000000641

Polit, D. F, \& Beck, C. T. (2004). Nursing research: Principles and methods (7th ed.). Willard.

Portia, W. (2019, 1 August). Nursing shortage: Foreign nurses provide aid to U.S. hospitals. https://nurse.org/articles/foreign-nurses-help-us-nursing-shortage

Raetong, P. (2012). Role change experience: From nursing students to registered nurses. Thai Journal of Nursing Council, 27(2), 51-62.

Roongruangsri, S., \& Sngounsiritham, U. (2015). Nursing faculty: Challenging the personal competency. Nursing Journal, 42(supplement), 214-221.

Sapkota, A., Poudel, U. K., Pokharel, J., Ghimire, P., Sedhain, A., Bhattarai, G. R., Thapa, B., \& Tulza, K. C. (2019). Factors associated with job satisfaction among graduate nursing faculties in Nepal. BMC Nursing, 18(58), 1-10. https://doi.org/10.1186/s12912-019-0379-2

Soomro, A.A., Breitenecker, R.J. \& Moshadi Shah, S.A. (2018). Relation of work-life balance, work-family conflict, and family-work conflict with the employee performance-moderating role of job satisfaction. South Asian Journal of Business Studies, 7(1), 130-146. https://doi.org/10.1108/SAJBS-02-2017-0018

Summawart, S. (2000). Implemented mentorship in nurse educator. Ramathibodi Nursing Journal, 6(1), 52-67.

Summers J. A. (2017). Developing competencies in the novice nurse educator: An integrative review. Teaching and Learning in Nursing, 12(4), 263-276. https://doi.org/10.1016/j.teln.2017.05.001

Svastdi-Xuto, P., \& Wangsukpisan, A. (2019). Transition experiences of nursing students' clinical initial practice. The Journal of Faculty of Nursing Burapha University, 27(3), $\quad$ 32-42.

Thaneenat, N.S. (2018). USC-service learning model: For student development in Thailand 4.0. Journal of Education Studies, 46(3), 325-344.

Thanisorn, Y. (2018). People's participation affecting local development in Nakhon Nayok province. Journal of MCU Nakhondhat, 5(2), 119-135.

Thomas, C. M., Bantz, D. L., Mclntosh, C. E. (2019). Nurse faculty burnout and strategies to avoid it. Teaching and Learning in Nursing, 14,(2), 111-116. https://doi.org/10.1016/j.teln.2018.12.005

van Manen, M. (1990). Researching lived experience. The Althouse Press.

van Manen, M. (2015). Researching lived experience: Human science for an action sensitive pedagogy (2nd Ed.). Left Coast Press.

Yang, J., Xu, X., Chen, Y., Shi, Z., \& Han, S. (2016). Trait self-esteem and neural activities related to self-evaluation and social feedback. Scientific Reports, 6, 1-10. https://doi.org/10.1038/srep20274 